\title{
Democracia digital e redes sociais: Twitter como filtro de informação política
}

\section{Danilo Rothberg}

\section{Resumo}

A internet, com seus recursos multimídia e de hipertexto, pode ser um suporte para a apresentação de informações de maneira atraente, capaz de contribuir para 0 aprofundamento da democracia. Inovação recente, as redes sociais têm operado inclusive como meio de atrair o interesse do público para informações sobre políticas públicas. Este texto apresenta e discute os resultados de um estudo empírico que avaliou, através de análise de conteúdo, a abrangência e a profundidade das informações oferecidas pelo governo do Estado de São Paulo e pelo Governo Federal em textos noticiosos acessados através do Twitter para divulgar propósitos, linhas de ação e limites de políticas públicas das áreas de assistência social, saúde, educação e meio ambiente. Os resultados indicam que as informações disponíveis tendem a se concentrar majoritariamente nos aspectos de objetivos, recursos e ações atuais no âmbito das políticas, ao passo que são notavelmente escassos os dados sobre recursos planejados, relações entre custo e efetividade e satisfação do usuário.

\section{Palavras-Chave}

Redes sociais. Comunicação pública. Informação. Políticas públicas.

Danilo Rothberg | danroth@uol.com.br Doutor em Sociologia pela Unesp - Universidade Estadual Paulista. Docente da Faculdade de Arquitetura, Artes e Comunicação da Unesp (Bauru, São Paulo, Brasil).

\section{Introdução}

A internet, com seus recursos multimídia e de hipertexto, pode ser um suporte para a apresentação de informações de maneira atraente, capaz de contribuir ao aprofundamento da vivência democrática. $\mathrm{E}$ a oferta de dados em abordagens diferenciadas, dimensionadas de acordo com variados níveis de interesse e habilidades cognitivas, pode contribuir para otimizar o esforço de obtenção de perspectivas para se obter uma compreensão mais acurada dos desafios a serem enfrentados pela gestão pública na atualidade. Inovação recente, as redes sociais têm operado inclusive como meio de atrair 0 interesse do público para informações sobre políticas públicas.

Este texto apresenta e discute os resultados de um estudo empírico que avaliou, em caráter comparativo, a abrangência e a profundidade das informações oferecidas pelo governo do Estado de São Paulo e pelo Governo Federal em textos noticiosos acessados através da rede social Twitter para divulgar propósitos, linhas de ação e 
limites de políticas públicas de impacto imediato para a cidadania, das áreas de assistência social, saúde, educação e meio ambiente.

Hospedados em diversas páginas de portais eletrônicos de governo, os textos noticiosos com informações sobre políticas públicas que tiveram sua leitura indicada por tweets foram avaliados no âmbito de 14 categorias: antecedentes das políticas; diagnósticos; objetivos; métodos; recursos atuais; ações atuais; recursos planejados; ações planejadas; eficiência; eficácia; impacto; custo-efetividade; satisfação do usuário; equidade.

0s resultados encontrados a respeito da qualidade da comunicação pública digital indicam que as informações disponíveis tendem a se concentrar majoritariamente em objetivos, recursos e ações atuais, ao passo que são notavelmente escassos os dados sobre recursos planejados, relações entre custo e efetividade e satisfação do usuário. Em geral, os governos têm preferido divulgar informações simplificadas e tendem a se esquivar da exigência democrática de proporcionar dados que permitam maior transparência de gestão e accountability.

No percurso adotado aqui, em primeiro lugar são revisados aspectos teóricos que fundamentaram o estudo. Em segundo lugar, os resultados são apresentados e comentados. Por fim, são postas breves sugestões para 0 aperfeiçoamento da qualidade da informação sobre políticas públicas em portais eletrônicos de governo.

\section{Democracia digital, teoria democrática e informação}

Há apenas 17 anos, em 30 de abril de 1995, a internet começava sua escalada de crescente uso público, após a National Science Foundation Network, que coordenou o avanço tecnológico responsável pela criação da World Wide Web nos Estados Unidos, ter eliminado as restrições que impediam a exploração comercial da rede (HARRIS; HANSEN, 2000).

Naquele momento, a rede já contava com quase um ano de experiência em sua utilização para fins cívicos. Isso porque, em 1994, já se encontrava em operação a primeira iniciativa de democracia digital de que se tem notícia, o Minnesota Politics and Public Policy E-Mail Forum (MN-Politics), uma lista de discussão por e-mails, sem moderadores, criada para facilitar a troca de informações sobre os candidatos ao Congresso dos Estados Unidos (BLUMLER; COLEMAN, 2001). 0 MN-Politics ${ }^{1}$ continua ativo, mas agora explorando os recursos atuais: blogs, wikis e fóruns.

Escrevendo sobre os primeiros cinco anos de uso da internet para 0 aprofundamento democrático, Cavanaugh (2000, p. 232) comemorava as realizações que traziam o potencial de "melhorar 
a qualidade da vida cívica", desde que as políticas públicas fossem "cuidadosamente construídas" a fim de possibilitar a utilização da rede para revolucionar a deliberação antes possível somente no modo tradicional face a face. "Sem atenta reflexão, a promoção das novas tecnologias de comunicação para reparar a desconexão entre 0 público e o governo pode criar uma visão muito simplificada dos cidadãos como meros clientes, compradores ou consumidores de serviços", profetizava Cavanaugh (2000, p. 232); ele sustentava que o já então proeminente uso da internet em campanhas eleitorais poderia frustrar as expectativas em torno da rede como meio para os cidadãos "[...] buscarem uma base comum para cautelosamente avaliarem, juntos, questões ligadas às políticas públicas".

Atualmente, o uso intenso e preferencial da internet em todo o mundo para funções de governo eletrônico, como pagamento de taxas e tributos, obtenção de declarações, certificados, licenças e informações legais parece ter contribuído para indicar que o compartilhamento da decisão pública pode ter ficado para trás entre as prioridades na exploração da rede pelos governos democráticos. 0 potencial de uso da internet como suporte de democracia digital ainda aguarda oportunidades para se expandir na forma de consultas públicas, fóruns e outros mecanismos para receber 0 input dos cidadãos, e sobretudo na provisão de informações substantivas sobre 0 desempenho na gestão de políticas públicas para os cidadãos em geral serem capazes de avaliar e dialogar sobre a performance de mandatários eleitos (UNITED NATIONS, 2005). No Brasil e na América Latina, a tendência também se verifica (BRAGA, 2007; BRAGATTO; VEIGA, 2006; DUJISIN, 2004; MARQUES; MIOLA, 2007; SILVA, 2005).

Uma questão relevante no contexto diz respeito à qualidade da informação disponível para a formação da opinião pública (SAMPAI0; MAIA; MARQUES, 2011; MAIA, 2008). A disponibilidade de informação para fundamentar a formação, com liberdade, de perspectivas próprias sobre a adequação de políticas públicas é necessária para a manutenção da vitalidade de uma democracia. Daí este estudo ter se voltado para verificar a qualidade da informação sobre políticas públicas que os usuários dos perfis do governo federal e do governo do Estado de São Paulo acessam via Twitter.

Os estudos sobre o uso do Twitter na política já são numerosos, inclusive no Brasil (AGGIO, 2011; CERVI; MASSUCHIN, 2011; MARQUES, 2011; NICOLÁS; BECHER; BRAGA, 2011). Embora haja uma grande diversidade de propósitos entre eles, não seria descabido arriscar aqui uma generalização para sustentar que, em geral, a preocupação tem sido verificar em que medida a gestão de um perfil no Twitter pode alavancar candidaturas, ao promover ideias dos candidatos, criar comunidades em torno de suas propostas, atrair votos e intensificar relações entre simpatizantes e eleitores e entre estes e seus candidatos, além de ampliar a base de propagação de críticas aos adversários eleitorais. 
Menos estudado é o Twitter como filtro de informação sobre política, e essa lacuna deve existir basicamente devido à limitação dos 140 caracteres comportados em cada tweet. Na própria rede social, não seria possível veicular abordagens substantivas sobre realizações no campo da administração pública. E o relacionamento efetivo entre cidadão e governo, na forma de perguntas e respostas sobre a disponibilidade de serviços públicos e manifestações diversas como reclamações, elogios, solicitações e sugestões, raramente ocorre nos tweets postados nos perfis de governo, de forma que permanece a necessidade de estudos que identifiquem maior frequência de mensagens dessa natureza e assim constituam um corpus apropriado de análise.

À luz dos resultados do estudo aqui descrito, notamos, no entanto, que muitos governos têm investido em seus perfis no Twitter como forma de compor um índice unificado para conduzir 0 acesso a informações disponíveis em textos noticiosos sobre fatos e acontecimentos recentes, relacionados à diversidade de políticas públicas executadas nas várias áreas de gestão pública.

0 tweet funciona como um título que atrai a leitura para uma abordagem mais ampla sobre determinada ação sistemática de governo. Em um curto período, a lista de títulos, por assim dizer, chega a dezenas de links para textos produzidos pelas assessorias de comunicação pública para divulgar fatos pertinentes à execução de políticas públicas, geralmente aqueles que resultam em benefícios imediatos aos cidadãos, como serviços públicos nas áreas de assistência social, saúde, educação e meio ambiente. Vale ressaltar que a produção dessas páginas pode não ter relação com sua posterior citação no Twitter. No entanto, 0 Twitter é utilizado como porta de acesso à informação antes dispersa por amplos portais eletrônicos de governo. Se o foco de estudo se der sobre a carga cognitiva de dados sobre políticas públicas disponível ao usuário que se sirva do perfil de um governo no Twitter para se informar, a questão de pesquisa se torna investigar qual é, afinal, a qualidade da informação sobre gestão pública à qual 0 Twitter se torna instrumento de acesso.

Qualidade de informação é pensada no contexto deste estudo em relação a um ideal normativo que, embora difícil de caracterizar objetivamente, subjaz às considerações teóricas sobre democracia deliberativa delineadas em sínteses como a de Sampaio, Maia e Marques (2011, p. 218), para quem a deliberação ampliada, que deve ocorrer com mais frequência na sociedade, é aquela "mantida por múltiplos momentos participativos de pequena escala que acontecem em períodos distintos, todos colaborando para a conversação pública, descentralizada e sem sujeito", de forma a mobilizar a razão pública e conferir substância à inserção dos cidadãos na vida cívica.

Ressalte-se, inclusive, que a comunicação pública digital, nos quadros de amplos sítios 
criados e mantidos por governos na internet para 0 atendimento do interesse coletivo na informação sobre gestão pública, pode levar à superação dos termos clássicos em que as mídias comerciais seriam, a despeito das limitações impostas pelas rotinas industriais da notícia, as principais fontes de referência do debate público. A informação com qualidade, uma vez tornada disponível e acessível pela coletividade, respeitando-se as diferentes habilidades cognitivas e os hábitos de uso de internet dos diversos públicos, pode contribuir de maneira significativa para reduzir o poder das mídias comerciais na delimitação de debate público, ao constituir uma alternativa como fonte para a formação de cidadãos capazes de se envolver com responsabilidade em deliberações ampliadas. A centralidade das mídias comerciais na sociedade contemporânea, tema tão frequente nos estudos de comunicação e política, teria que ser revista caso a comunicação pública viesse de fato a constituir uma fonte de qualidade, acessível e confiável. A questão é complexa, e uma apreciação mais completa sobre ela não cabe nos limites deste artigo. Inclusive, a comunicação pública digital exigiria, neste caso, autonomia frente às ingerências de mandatários centrados nos imperativos da propaganda política. A comunicação pública deve se constituir como pública, não como comunicação estatal (DUARTE, 2007).
Como avaliar a qualidade da carga significativa de informações disponíveis nos portais de governo sobre políticas públicas, em particular aquelas filtradas pelo Twitter em listas de tweets postados por perfis de governo, é uma tarefa a ser resolvida do ponto de vista metodológico. Avançamos na próxima seção com o propósito de delinear a metodologia aplicada em nosso estudo.

\section{Twitter como fonte de informação e meios para sua análise}

Com a contribuição da literatura sobre avaliação de políticas públicas, especialmente Arretche (1998), Carvalho (2003), Costa e Castanhar (2003), Faria (2005), Souza (2003) e Trevisan e van Bellen (2008), construímos uma lista de 14 categorias a serem consideradas na análise de conteúdo das informações sobre políticas públicas disponíveis nos textos da amostra selecionada, que provêm de 121 abordagens noticiosas distintas, cada uma delas acessada por um tweet correspondente, publicadas durante 0 mês de junho de 2011 sobre fatos e acontecimentos ligados a políticas públicas das áreas de assistência social, saúde, educação e meio ambiente no âmbito do Governo Federal (57 textos) e governo do Estado de São Paulo (64 textos). ${ }^{2}$ Estas áreas foram escolhidas por possivelmente possuírem impacto mais imediato para a percepção da qualidade de condições de vida. 
O link para os perfis de governo no Twitter está disponível na página inicial dos respectivos portais. ${ }^{3}$ Criado em abril de 2009, o perfil do governo paulista, @governosp, possuía, em agosto de 2012, 40.760 seguidores e seguia 97 perfis. A responsabilidade por sua manutenção é da Subsecretaria de Comunicação do governo estadual. Já o perfil federal, @ portalbrasil, foi criado em março de 2010 e possuía, em agosto de 2012, 130.760 seguidores e seguia 226 perfis. A responsabilidade por sua manutenção é da Secretaria de Comunicação Social da Presidência da República.

Cada uma das 121 abordagens estudadas se refere a aspectos de uma política específica e foi caracterizada por um indicador para cada uma das 14 categorias de análise empregadas, que variou entre "0" (ausência de informação relacionada), "1" (presença de informações superficiais, em geral com até 200 caracteres com espaços) e "2" (presença de informações mais aprofundadas). Desta forma, uma política pública apresentada com o máximo de informações obteria, segundo a lista proposta, 28 pontos (14 categorias $\mathrm{x}$ dois pontos). 0 número de pontos efetivamente obtido na avaliação de informações a respeito de cada política, quando considerado em relação ao total de 28 pontos, gerou um número percentual correspondente ao grau de abrangência e profundidade das abordagens de comunicação presentes nos sítios estudados. Este número foi denominado Índice de Qualidade da Informação (IQI). As categorias são as seguintes:
1. Antecedentes - Condições sociais, econômicas, políticas e ambientais que antecederam e, portanto, motivaram a criação e a implementação de uma política.

2. Diagnósticos - Determinada compreensão dos problemas a serem enfrentados que fundamenta a execução de uma política.

3. Objetivos - Cenário genérico a ser atingido, não caracterizado necessariamente em termos quantitativos.

4. Metas - Números, estatísticas e projeções.

5. Recursos atuais - Recursos materiais, financeiros ou humanos atualmente empregados, caracterizados com objetividade.

6. Ações atuais - Ações objetivas em andamento, imprescindíveis à implementação de uma política pública.

\section{Recursos planejados - Recursos} materiais, financeiros ou humanos empregados em um futuro especificado, caracterizados com objetividade.

\section{Ações planejadas - Ações programadas} para um futuro especificado, imprescindíveis à implementação de uma política pública. 
9. Eficiência - Avaliação da relação entre o esforço de implementação de uma dada política e seus resultados.

10. Eficácia - Avaliação da relação entre objetivos e instrumentos de uma política pública e os resultados efetivamente verificados.

11. Impacto (efetividade) - Avaliação da relação entre a implementação de uma política e seus impactos nos termos de mudança real nas condições sociais anteriores.

\section{Custo-efetividade - Comparação entre} formas alternativas de ação para obtenção de determinados resultados.

\section{Satisfação do usuário - Avaliação da} qualidade do atendimento segundo os próprios beneficiários.

\section{Equidade - Avaliação da distribuição dos} benefícios, que deve ocorrer de maneira justa e compatível com as necessidades dos diversos públicos.

\section{Resultados}

Os 64 textos com informações sobre políticas públicas das áreas de assistência social, saúde, educação e meio ambiente acessados através do perfil do governo do Estado de São Paulo durante 0 mês de junho de 2011 no Twitter foram avaliados com a metodologia acima descrita e obtiveram, em média, $32 \%$ do total de dados que seria possível atingir caso houvesse informações completas para todas as políticas e em todas as categorias consideradas, ou seja, se cada um dos textos estudados obtivesse os 28 pontos possíveis conforme a metodologia empregada (dois pontos para cada uma das 14 categorias formuladas). 0 IQI pode ser tido como indicador da insuficiência dos dados presentes nos textos analisados em relação ao que seria desejável, do ponto de vista da disponibilidade de informação tida como necessária no contexto teórico-metodológico da pesquisa, para fundamentar uma performance mais vigorosa nos campos da deliberação ampliada.

Há diferenças significativas entre as categorias de informação. 0 eixo vertical do Gráfico 1 registra 0 percentual de políticas, entre as 64 analisadas, que registraram ao menos informações superficiais (em extensão inferior a 200 caracteres) referentes a cada uma das 14 categorias de análise (eixo horizontal). Nota-se a prevalência de dados básicos sobre as políticas correspondentes às categorias "ações atuais"' (94\% das políticas analisadas possuem informações relacionadas), "objetivos" (64\%) e "eficiência" (59\%), ao passo que categorias como "satisfação do usuário" (6\%) e "custo-efetividade" $(0 \%)$ registraram pouca ou nenhuma informação.

Já as 57 políticas no perfil do Governo Federal no Twitter permitiram a obtenção de $25 \%$ do total de 
Gráfico 1 - Informações sobre políticas públicas, segundo categorias de análise, acessadas através do perfil do governo do Estado de São Paulo no Twitter em junho de 2011

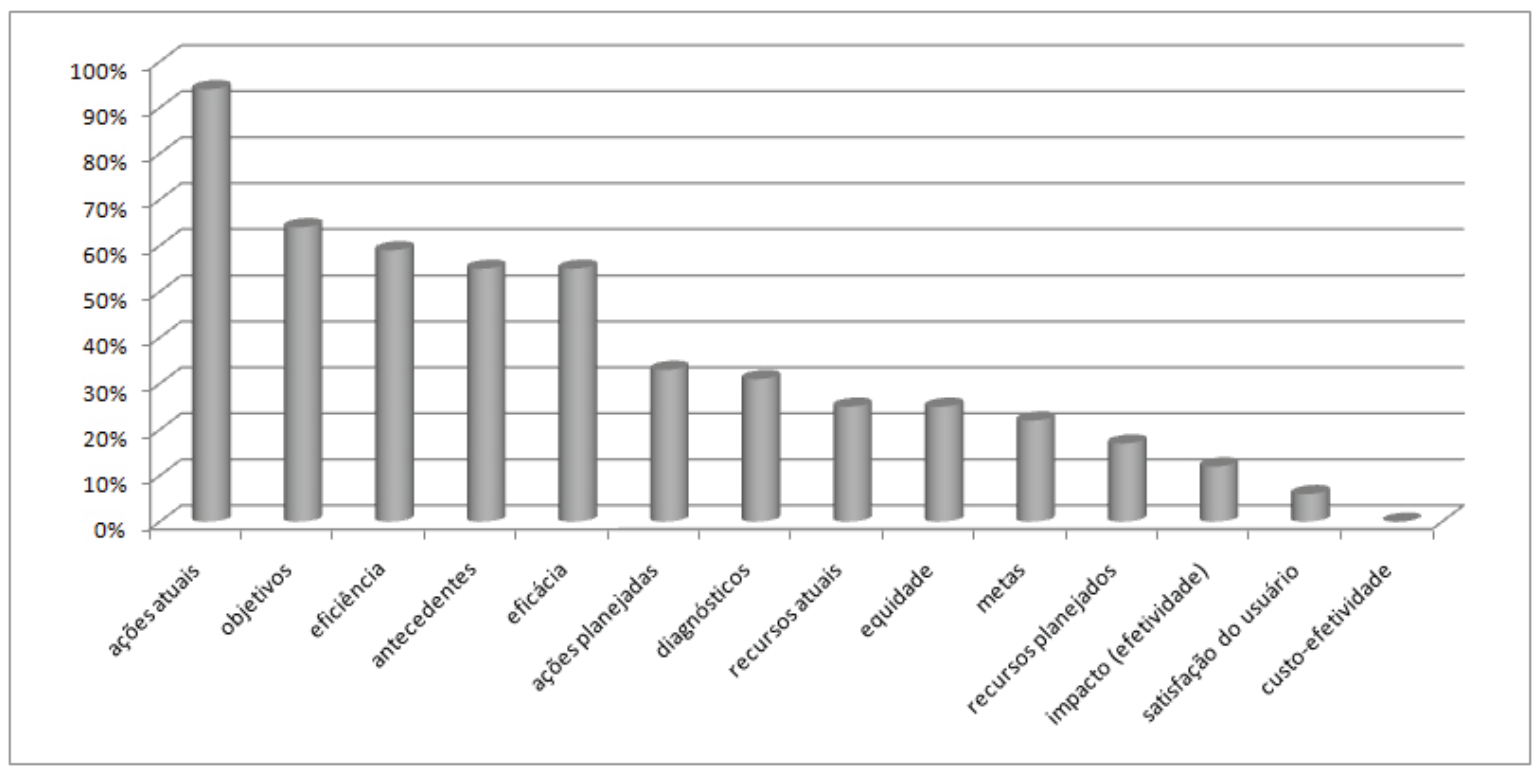

Fonte: elaboração do autor.

dados que seria possível atingir, caso houvesse informações completas para todas as políticas e em todas as categorias consideradas, o que representa um IQI levemente inferior ao registrado para o Estado de São Paulo.

Novamente, prevaleceram informações básicas sobre as políticas, apresentadas em torno das categorias "objetivos" (74\% das 57 políticas analisadas possuem dados referentes) e "ações atuais" (63\%), ao passo que as categorias "satisfação do usuário" (3\%) e "custo-efetividade" (0\%) apresentaram pouca ou nenhuma informação (Gráfico 2).

Similaridades significativas emergem da comparação entre o desempenho dos dois governos na difusão de informação através do Twitter. De forma geral, o IQI, de 32\% no perfil do governo paulista e 25\% no Governo Federal, é baixo em relação ao que poderia ser considerado adequado, no contexto teórico-metodológico da pesquisa, para fundamentar a deliberação política, ainda que pensada nos termos da deliberação ampliada, praticada sem objetivos definidos, com temáticas aleatórias e em fóruns transitórios.

Segundo a interpretação que propomos para este aspecto dos resultados, a insuficiência de informações detectada igualmente em ambos os portais estudados pode ser atribuída a uma combinação de dois fatores.

Em primeiro lugar, está a relativa ausência de um referencial objetivo para orientar a produção de conteúdo em portais eletrônicos de governo. Não seria descabido supor que a maioria dos editores 


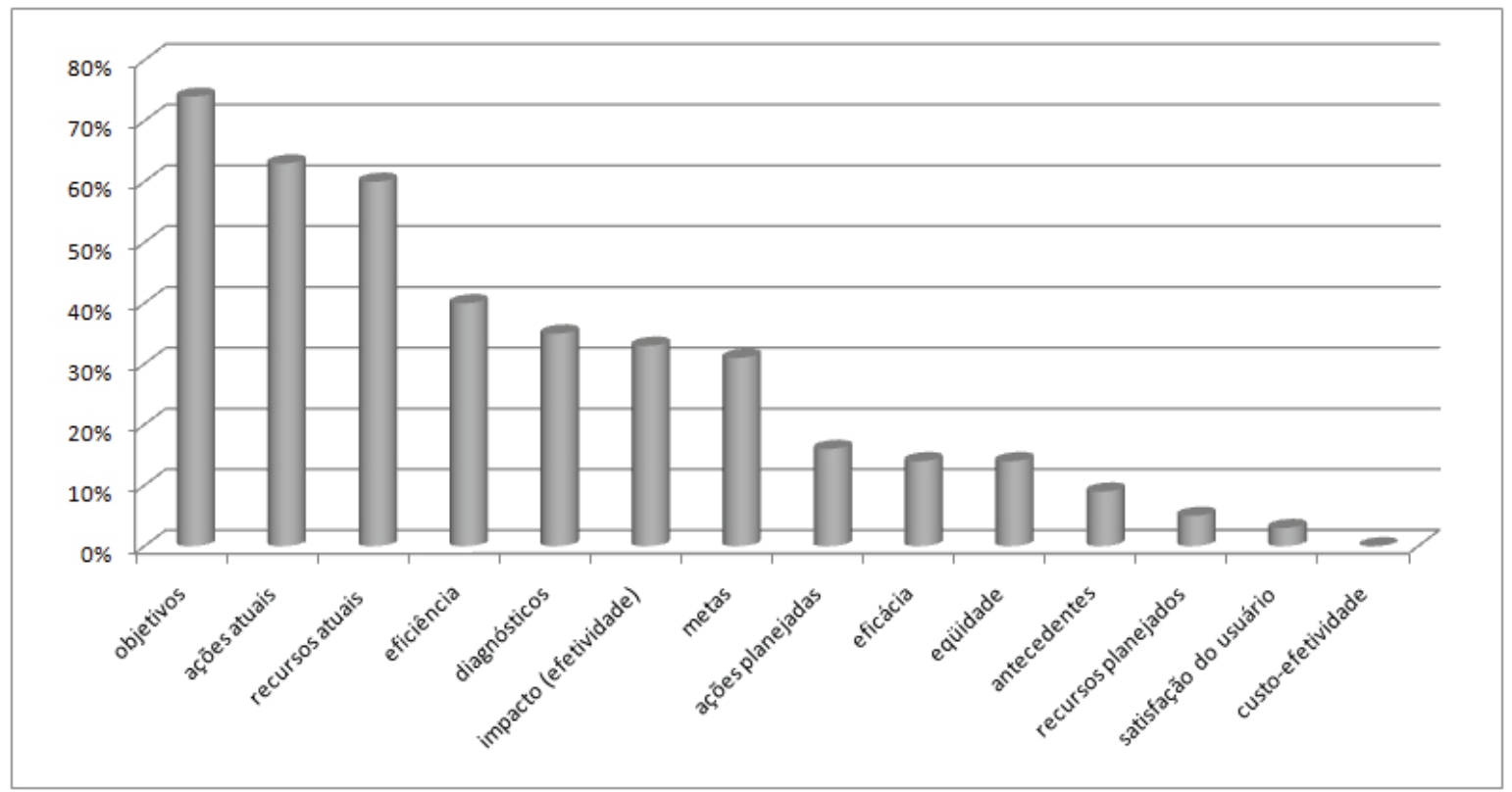

Fonte: elaboração do autor.

de conteúdo seja composta por jornalistas, formados no quadro dos limites de tempo e espaço impostos pelas rotinas industriais de produção da notícia (SOUSA, 2002; WOLF, 2008).

Em segundo lugar está a associação entre sistema político-institucional e modelo de mídia apontada nos trabalhos de Hallin e Mancini (2004, 2012), que, embora originalmente pensada para relacionar as características de cultura política de um país ao seu formato de exploração de mídias comerciais e de serviço público de radiodifusão, pode ser refeita para explicar por que razão, em determinado país, a importância da disponibilidade pública da informação sobre gestão pública tende a não ser reconhecida. 0 pluralismo, por exemplo, tenderia a ser mais prezado em países de tradição democrática mais longa e consolidada, favoráveis à ideia de que cada corrente política deve encontrar uma forma adequada de expressão nas mídias, sejam elas comerciais ou públicas. Países com menor tradição democrática, ao contrário, aceitariam a exclusão de determinadas vozes do debate público, porquanto elas aparentem ser minoritárias ou não razoáveis segundo um suposto entendimento da maioria. Na atualização do conceito, podemos sustentar que a relevância, para 0 aprofundamento da democracia, da própria existência de informação diversificada sobre a gestão de políticas públicas nos portais eletrônicos de governo tende a ser menos reconhecida no Brasil.

Estudos empíricos comparativos internacionais seriam necessários para elucidar a validade 
Gráfico 3 - Informações sobre políticas públicas, segundo categorias de análise, acessadas através do perfil dos governos paulista e federal brasileiro no Twitter em junho de 2011

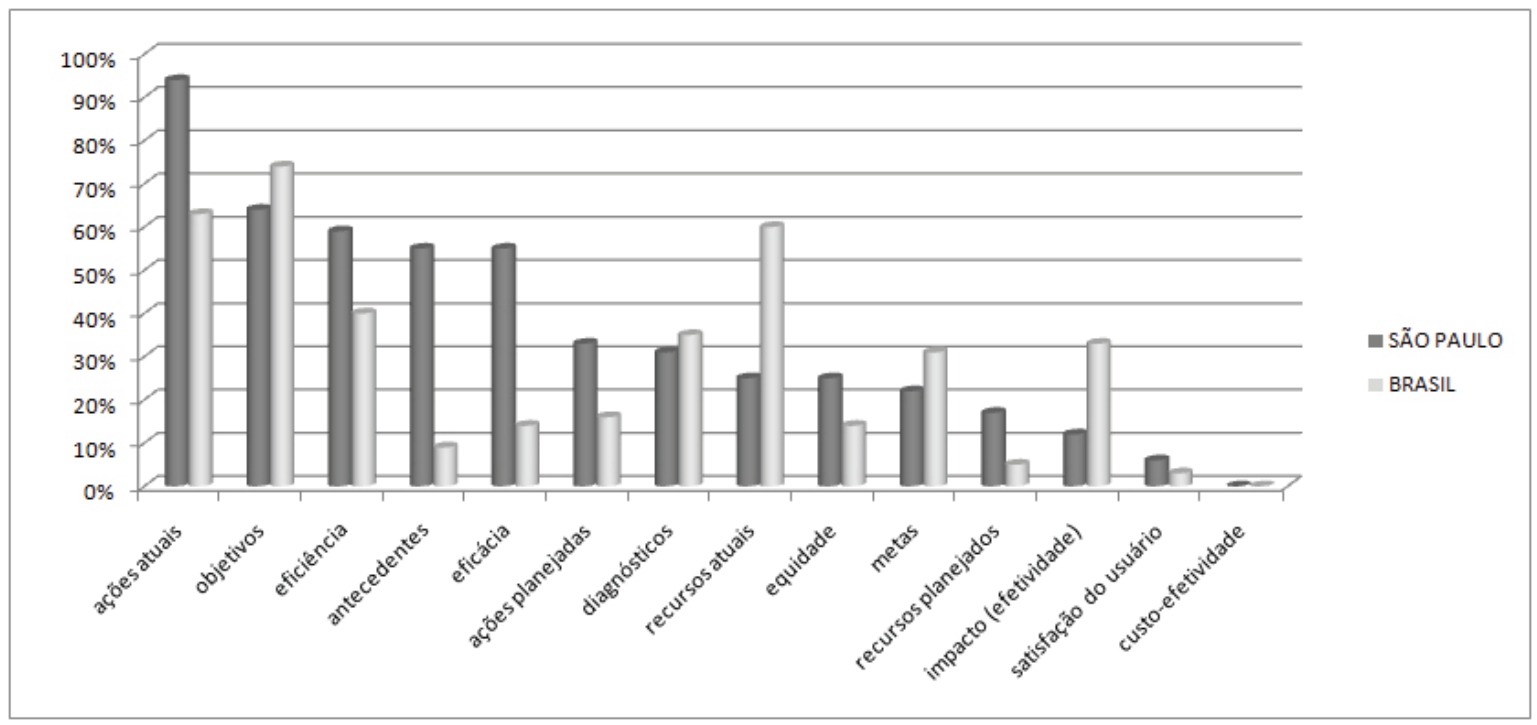

Fonte: elaboração do autor.

desta interpretação. Além disso, é forçoso reconhecer que esta forma de interpretar 0 fenômeno da insuficiência de informações em portais eletrônicos de governo poderia ser fragilizada pelo confronto com as previsíveis considerações de editores de conteúdo sobre a presumida falta de recursos dos usuários para ler sobre o assunto, sejam elas de tempo, atenção, interesse ou habilidades cognitivas. $\mathrm{Ou}$ seja, um editor de conteúdo de portal de governo pode tentar justificar a escassez de informação com a desculpa de que usuário nenhum teria vontade, energia ou capacidade para apreender informação sobre, por exemplo, as 14 categorias aqui propostas. Mas semelhante argumentação encobriria a possibilidade de que 0 vetor do fenômeno seja uma determinada compreensão sobre a qualidade da democracia desejável em um país, o nível de informação a ela necessário e a missão pública das tecnologias no contexto das democracias digitais contemporâneas.

Outras similaridades requerem interpretações adicionais. Como já indicado, as duas primeiras categorias com mais disponibilidade de informações são "ações atuais" e "objetivos", alternando-se apenas sua posição; as duas últimas categorias também são as mesmas nos perfis analisados: "satisfação do usuário" e custoefetividade" (Gráfico 3). A categoria "eficiência" está bem posicionada em ambos os perfis (terceiro no governo paulista e quarto no perfil federal), enquanto a categoria "recursos planejados" está mal posicionada em ambos ( $11^{\circ}$ em São Paulo e $12^{\circ}$ na esfera federal).

"Ações atuais" e "objetivos" dizem respeito a dados essenciais sobre as políticas. São os 
mais frequentes, em tese, porque se referem exatamente ao seu propósito e aplicação. Já a presença de dados sobre "eficiência" parece denotar a preocupação dos gestores de conteúdo dos portais digitais em propagar a imagem de que os governos são capazes e fazem tudo que seja possível para os serviços públicos atenderem de fato quem deles precisa. Nesse sentido, os portais digitais seriam usados menos como instrumento de accountability e mais como ferramenta de propaganda política. Embora não haja necessariamente contradição entre estas duas finalidades, as técnicas para a efetivação de um e de outro tendem a ser diferentes.

Informações sobre "recursos planejados", embora sejam relevantes para se avaliar a seriedade do planejamento envolvido na implementação de uma política pública, podem ser escassas nos portais digitais porque os governos não querem se comprometer com promessas possíveis de não serem cumpridas, nem dar munição para os adversários cobrarem promessas eventualmente quebradas.

\footnotetext{
"Satisfação do usuário" e "custo-efetividade", categorias de informação praticamente ausentes na amostra estudada, podem indicar a presença de traços da cultura política de uma democracia em consolidação, em que, novamente, o pluralismo de informações não é um valor necessariamente apreciado. Indicadores de "satisfação do usuário", embora fundamentais para a avaliação de qualquer política pública, parecem não ser aferidos (o que
}

demandaria ações custosas) ou revelados (por serem possivelmente negativos) pelos governos em seus portais digitais. Já as informações sobre "custo-efetividade" exigiriam o exame objetivo de alternativas e a apresentação de justificativas sobre a linha de ação escolhida. Os governos parecem se esquivar da admissão de que adotaram apenas uma entre muitas alternativas disponíveis, preterindo outras por razões específicas, que assim permanecem ocultas. $\mathrm{Ou}$ seja, os portais digitais de governo não concedem ao cidadão a possibilidade de saber mais sobre os efeitos da realização da política como meio de negociação entre interesses diversos, que oferecem alternativas de ação com méritos distintos. Para o público em geral, a política executada pelo governo deve figurar como a melhor opção possível ou, de preferência, a única saída.

Em torno das oito políticas representadas na porção central do Gráfico 3, há discrepâncias significativas em relação ao tratamento verificado em cada um dos portais de governo estudados. 0 Governo Federal se destacou pela oferta de informações sobre "recursos atuais" humanos, materiais e financeiros empregados nas políticas enfocadas, na forma de números e abordagens detalhadas, e sobre "impacto (efetividade)", com dados provenientes de macro avaliações sobre os efeitos duradouros das políticas. No portal do governo paulista, as categorias "antecedentes" e "eficácia" obtiveram números mais altos, o que pode denotar preocupação com a exposição do contexto que motivou a criação das políticas e a verificação das mudanças desejadas por sua execução. No 
entanto, explicações mais abrangentes para essas diferenças ainda precisam ser buscadas.

Note-se, inclusive, que não foram identificadas diferenças significativas na disponibilidade de informações referentes a cada uma das quatro diferentes áreas de políticas públicas estudadas: assistência social, saúde, educação e meio ambiente. Por isso optamos por apresentar somente 0 desempenho geral obtido em média no conjunto das quatro áreas em relação à qualidade de informação correspondente a cada uma das 14 categorias de análise empregadas.

\section{Considerações finais e recomendações}

0 desenho de pesquisa que propusemos teve como pressuposto o reconhecimento de que 0 Twitter, ferramenta que admite vários usos para a difusão e troca de mensagens sobre a política formal, com potencial para a formação de comunidades de eleitores e simpatizantes, tem sido usado inclusive para constituir, de maneira inovadora, um filtro de informações sobre políticas públicas. Este uso decorre da postagem constante de tweets por gestores de perfis de governos, que proveem links para acesso de textos noticiosos sobre políticas públicas coordenadas por secretarias, ministérios, autarquias e outras instâncias de gestão pública. 0 Twitter funciona como uma espécie de sumário para acessar informações de governo, um filtro relevante que orienta a navegação seletiva entre centenas de textos que detalham o funcionamento de serviços públicos e a performance de governo em sua gestão e oferta.

Os dados empíricos obtidos em nosso estudo indicam que os textos acessados via Twitter se caracterizam pela insuficiência de informações sobre políticas públicas das áreas de assistência social, saúde, educação e meio ambiente, ao menos em relação às 14 de categorias de análise propostas: antecedentes; diagnósticos; objetivos; métodos; recursos atuais; ações atuais; recursos planejados; ações planejadas; eficiência; eficácia; impacto; custo-efetividade; satisfação do usuário; equidade. Em média, as páginas do governo paulista e do Governo Federal apresentaram, respectivamente, $32 \%$ e $25 \%$ dos dados que seriam adequados para fundamentar uma inserção mais vigorosa no campo da deliberação pública.

Ao interpretar estes números, sustentamos que a escassez de referenciais para os editores de conteúdo dos portais eletrônicos de governo pode ser a causa preponderante das insuficiências detectadas. E, diante da falta de diretrizes, critérios típicos das rotinas industriais de produção da notícia comuns ao jornalismo comercial seriam adotados.

Para enfrentar o problema, sugerimos que as 14 categorias de análise aqui propostas poderiam ser utilizadas como critérios para a produção de informações sobre políticas públicas a serem veiculadas em portais eletrônicos de governo. Ao orientar a busca de dados para compor 
os textos, os editores de conteúdos poderiam empregar critérios para abranger as dimensões indicadas, com aporte da ciência política, no âmbito da área de avaliação de políticas públicas. Isto exigiria independência dos governos, no contexto do que as ciências da comunicação delimitam como comunicação pública, não estatal. A convergência interdisciplinar entre ciência política e ciências da comunicação pode ser fértil como vetor de conhecimentos sobre como construir e manter portais eletrônicos de governo capazes de corresponder às exigências da cidadania enquanto direito à informação nas democracias contemporâneas.

Finalmente, os tweets poderiam ser explorados como entradas de um índice não só para determinados textos com informações sobre políticas públicas, mas também para determinados aspectos das políticas. 0 desafio de prover dados nas 14 dimensões aqui propostas inclui o desafio de construir páginas com recursos de hipertexto e multimídia capazes de sustentar 0 interesse do público em geral. Desta forma, uma única página e um único texto não dariam conta de todas as dimensões. Seria necessário dispor os dados por páginas diferenciadas, com fácil navegação entre elas. Vale apontar que abranger as 14 dimensões não implica a produção de abordagens enciclopédicas. Em nossa metodologia, consideramos que informações em profundidade adequada já são viáveis utilizando-se pouco mais de 200 caracteres, em média, o que equivale a duas ou três linhas de texto. Com criatividade, os tweets poderiam ligar-se à diversidade de aspectos relevantes das políticas públicas, fazendo do Twitter uma ferramenta de enorme valor para dinamizar 0 acesso a informações sobre gestão pública.

\section{Referências}

AGGIO, C. As campanhas políticas no Twitter: uma análise do padrão de comunicação política dos três principais candidatos à presidência do Brasil em 2010. In: ENCONTRO DA ASSOCIAÇÃO BRASILEIRA DE PESQUISADORES EM COMUNICAÇÃO E POLÍTICA, 4, 2011. Rio de Janeiro. Anais... Rio de Janeiro: Compolítica, 2011.

ARRETCHE, M. Tendências no estudo sobre avaliação. In: RIC0, E. M. Avaliação de políticas sociais: uma questão em debate. São Paulo: Cortez, 1998.

BLUMLER, J. G.; COLEMAN, S. Realising democracy online: a civic commons in cyberspace. London, England: IPPR, 2001.

BRAGA, S. S. Podem as novas tecnologias de informação e comunicação auxiliar na consolidação das democracias? Um estudo sobre a informatização dos órgãos legislativos na América do Sul. Opinião Pública, Campinas, v. 13, n. 1, p. 1-50, jun. 2007.

BRAGATTO, R. C.; VEIGA, L. Participação democrática e novas tecnologias de comunicação: mapeando diretrizes políticas e o uso da internet pelos governos do Brasil e da Argentina. In: CONGRESSO ANUAL DA ASSOCIAÇÃO BRASILEIRA DE PESQUISADORES DE COMUNICAÇÃO E POLÍTICA, 1., 2006, Salvador. Anais... Salvador: Universidade Federal da Bahia, 2006. CARVALHO, S. N. Avaliação de programas sociais: balanço das experiências e contribuição para o debate. São Paulo em Perspectiva, São Paulo, v. 17, n. 3-4, p. 185-197, jul./dez. 2003.

CAVANAUGH, J. W. E-democracy: thinking about the impact of technology on civic life. National Civic 
Review, Hoboken (NJ), v. 89, n. 3, p. 229-234, Fall 2000.

CERVI, E. U.; MASSUCHIN, M. G. 0 uso do Twitter nas eleições de 2010: o microblog nas campanhas dos principais candidatos ao governo do Paraná.

Contemporanea, Salvador, v. 9, n. 2, p. 319-334, ago. 2011.

COSTA, F. L.; CASTANHAR, J. C. Avaliação de programas públicos: desafios conceituais e metodológicos. Revista de Administração Pública, Rio de Janeiro, v. 37, n. 5, p. $962-969$, set./out. 2003.

DUARTE, J. (Org.). Comunicação pública: Estado, mercado, sociedade e interesse público. São Paulo: Atlas, 2007.

DUJISIN, R. A. Tres perspectivas para observar el gobierno electrónico. In: DUJISIN, R. A.; VIGÓN, M. P. (Org.) América Latina Puntogob: casos y tendencias en gobierno electrónico. Santiago: FLACSO, 2004.

FARIA, C. A. P. A política da avaliação de políticas públicas. Revista Brasileira de Ciências Sociais, São Paulo, v. 20, n. 59, p. 97-109, out. 2005.

HALLIN, D. C.; MANCINI, P. Comparing media systems: three models of media and politics. Cambridge: Cambridge University Press, 2004.

HALLIN, D. C.; MANCINI, P. Comparing media systems beyond the western world. Cambridge: Cambridge University Press, 2012.

HARRIS, S.; HANSEN, A. The Internet: changing the way we communicate. In America's investment in the future: NSF celebrating 50 years. Arlington, VA, United States: National Science Foundation, 2000.

MAIA, R. C. M. A deliberação nos media: apontamentos conceituais. Comunicação \& Sociedade, São Bernardo do Campo, v. 30, p. 81-120, $1^{0}$ sem. 2008.

MARQUES, F. P. J. A. Estratégias de comunicação política online: uma análise do perfil de José Serra no Twitter. In: ENCONTRO ANUAL DA ASSOCIAÇÃO DE PÓSGRADUAÇÃO E PESQUISA EM CIÊNCIAS SOCIAIS, 35, 2011, Caxambu, MG. Anais... Caxambu, 2011.
MARQUES, F. P. J. A.; MIOLA, E. Internet e parlamento: um estudo dos mecanismos de participação oferecidos pelo Poder Legislativo através de ferramentas online. E-Compós, Brasília, v. 9, p. 1-20, ago. 2007.

NICOLÁS, M. A.; BECHER, A.; BRAGA, S. S. Elites políticas e NTICs: uma análise do uso da internet pelos candidatos aos governos estaduais e ao senado nas eleições brasileiras de outubro de 2010. In: ENCONTRO ANUAL DA ASSOCIAÇÃO DE PÓS-GRADUAÇÃO E PESQUISA EM CIÊNCIAS SOCIAIS, 35, 2011, Caxambu, MG. Anais... Caxambu, 2011.

ROTHBERG, D. Portais eletrônicos de governo e a contribuição da informação e da comunicação para a expansão da cidadania. In: Anais do $34^{\circ}$ Encontro Anual da Anpocs. Associação Nacional de Pós-Graduação e Pesquisa em Ciências Sociais. Caxambu, MG, 2010.

SAMPAIO, R. C.; MAIA, R. C. M.; MARQUES, F. P. J. A. Deliberações ampliadas ou restritas: perspectivas de integração. Comunicação \& Sociedade, São Bernardo do Campo, v. 32, n. 55, p. 203-229, jan./jun. 2011.

SILVA, S. P. Graus de participação democrática no uso da Internet pelos governos das capitais brasileiras. Opinião Pública, Campinas, v. 11, n. 2, p. 450-468, out. 2005.

SOUSA, J. P. Teorias da notícia e do jornalismo. Chapecó, SC: Argos, 2002.

SOUZA, C. "Estado do campo" da pesquisa em políticas públicas no Brasil. Revista Brasileira de Ciências Sociais, São Paulo, v. 18, n. 51, p. 15-20, fev. 2003.

TREVISAN, A. P.; BELLEN, H. M. Avaliação de políticas públicas: uma revisão teórica de um campo em construção. RAP - Revista de Administração Pública, Rio de Janeiro, v. 42, n. 3, p. 529-50, maio/jun. 2008.

UNITED NATIONS. UN global e-government readiness report 2005: from e-government to e-inclusion. Nova York, 2005.

WOLF, M. Teorias das comunicações de massa. São Paulo: Martins Fontes, 2008. 
Digital democracy and social networks: Twitter as a filter of political information

\section{Abstract}

The internet, with its hypertext and multimedia features, can be a support for the dissemination of information in an attractive way, which may contribute to the strengthening of democracy. Recent innovation, social networks have been explored also as a resource to attract the interest of the broader public to information about public policies. This paper presents and discusses the results of an empirical study which assessed, through content analysis, the breadth and depth of information offered by the Sao Paulo state government and the federal government in texts accessed through Twitter to publicize purposes, lines of action and limits of public policy in the areas of welfare, health, education and environment. The results indicate that the information available tend to focus mainly on goals, resources and current actions of policies, whereas there can be found few data on planned features, relation between cost and effectiveness and user satisfaction.

\section{Keywords}

Social networks. Public communication. Information. Public policies.

\section{Democracia digital y las redes sociales: el Twitter como filtro de la información política}

\section{Resumen}

La internet, con sus recursos multimedia e híper textuales, puede ser un apoyo para la presentación de la información de una manera atractiva, lo que puede contribuir para la profundización de la democracia. Innovaciones recientes, las redes sociales han funcionado también como un medio para atraer el interés del público por la información sobre las políticas públicas. Este artículo presenta y discute los resultados del estudio empírico que evaluó, mediante análisis de contenido, el alcance y la profundidad de la información ofrecida por el gobierno del estado de San Pablo (Brasil) y el gobierno federal en los textos informativos que pueden accederse a través de Twitter para dar a conocer las intenciones, líneas de acción y los límites de las políticas públicas en las áreas de bienestar social, salud, educación y medio ambiente. Los resultados indican que la información disponible tiende a centrarse principalmente en mostrar los objetivos, los recursos y las acciones de los proyectos actuales, mientras que son muy pocos los datos que especifiquen las características planeadas, las relaciones entre coste y eficacia y satisfacción del usuario.

\section{Palabras-Clave}

Redes sociales. Comunicación pública. Información; Políticas públicas. 
¿ecompós

www.e-compos.org. br

| E-ISSN 1808-2599 | 